\title{
Pelatihan Manajemen Usaha Bagi Kelompok Usaha Bersama (KUBE) Jupiter Jaya di Dusun Mavilla Rengganis Kabupaten Lombok Barat
}

\author{
Baiq Herdina Septika*,Tama Krisnahadi, Menik Aryani, \\ Yayang Erry Wulandari, Ira Dianti \\ Universitas Pendidikan Mandalika \\ *Corresponding Author: Herdina_virgo25@yahoo.com
}

\begin{abstract}
The purpose of this service activity is to increase the motivation of Community Business Groups and the competitiveness of products by providing business management training for Jupiter Jaya Joint Business Group (KUBE) in Mavilla Rengganis Village, West Lombok Regency. The methods of implementing this activity wereby lectures, discussions and mentoring. The lectures were consisted of delivering material on business management, namely packaging management, labeling management and business financial management. The participants in this activity were 10 members of Jupiter Jaya KUBE. For financial management, partners were given training in simple financial bookkeeping and given assistance in making business bookkeeping. The result of this service activityis that most of the participants can comprehend business financial management. It can be seen that more than $90 \%$ of participants are able to make financial bookkeeping. In addition, the partners also agreed to use pouch stand for fish crisp packaging. This is because the stand pouch is more practical in packaging, strong in design, very flexible in shape, economical in price, and more modern and attractive in appearance. For product brands, the partners also agreed to name the fish crisp brand as $d u a$ sekawan.
\end{abstract}

\begin{abstract}
Abstrak: Tujuan dari kegiatan pengabdian ini adalah untuk meningkatkan motivasi Kelompok Usaha Masyarakat dan daya saing produk dengan memberikan pelatihan manajemen usaha bagi Kelompok Usaha Bersama (KUBE) Jupiter Jaya Di Dusun Mavilla Rengganis Kabupaten Lombok Barat. Metode pelaksanaan kegiatan ini adalah ceramah, diskusi dan pendampingan. Ceramah terdiri dari penyampaian materi mengenai manajemen usaha yaitu manajemen kemasan, manajemen labeling dan manajemen keuangan usaha. Peserta dalam kegiatan ini adalah anggota KUBE Jupiter Jaya yang berjumlah 10 orang. Untuk manajemen keuangan, mitra diberi latihan membuat pembukuan sederhana dan diberikan pendampingan dalam membuat pembukuan usaha. Hasil dari kegiatan pengabdian ini adalah sebagian besar peserta memahami manajemen keuangan usaha. Hal ini terlihat lebih dari $90 \%$ peserta mampu membuat pembukuan usaha. Selain itu mitra juga sepakat menggunakan stand pouch untuk kemasan produk peyek ikan. Hal ini dikarenakan kemasan stand pouch lebih praktis, tampilan desain kuat, bentuknya sangat fleksibel, harga ekonomis, tampilan lebih modern dan menarik. Untuk merek produk, mitra juga sepakat memberikan nama merek peyek ikan dua sekawan.
\end{abstract}

\section{Article History:}

Received: 23-03-2021

Reviewed: 03-04-2021

Accepted: 12-04-2021

Published: 05-05-2021

Key Words:

Training, KUBE, Business

Management, Product

Quality.

\section{Sejarah Artikel: \\ Diterima: 23-03-2021 \\ Direview: 03-04-2021 \\ Disetujui: 12-04-2021 \\ Diterbitkan: 05-05-2021}

\section{Kata Kunci: \\ Pelatihan, KUBE, \\ Manajemen Usaha, \\ Kualitas Produk.}

How to Cite: Septika, B., Krisnahadi, T., Aryani, M., Wulandari, Y., \& Dianti, I. (2021). Pelatihan Manajemen Usaha Bagi Kelompok Usaha Bersama (KUBE) Jupiter Jaya Di Dusun Mavilla Rengganis Kabupaten Lombok Barat. Jurnal Pengabdian UNDIKMA, 2(1), 30-35. doi:https://doi.org/10.33394/jpu.v2i1.3587 


\section{Pendahuluan}

Pemberdayaan Usaha Kecil Menengah (UKM) merupakan salah satu andalan utama bagi ketahanan ekonomi suatu negara. Terbukti di masa krisis pada tahun 1998 dengan bertumbangan banyak usaha besar karena dililit hutang luar negeri dan biaya bahan baku impor meningkat secara drastis. Usaha kecil menengah mampu tetap bertahan terutama yang berorientasi ekspor justru meraup keuntungan yang luar biasa. Sebagian lagi bisa bertahan dengan berbagai cara karena kecilnya investasi dan modal yang berputar (Departemen Koperasi, 2008).

Dusun Mavilla Rengganis terletak di daerah Labuapi Lombok Barat, sekitar 15 menit dari kota mataram. Sebagian besar penduduknya membentuk Kelompok Usaha Bersama (KUBE). KUBE merupakan suatu kelompok yang dibentuk melalui proses kegiatan pemberdayaan masyarakat untuk melaksanakan kegiatan kesejahteraan sosial dan usaha ekonomi dalam semangat kebersamaan sebagai sarana untuk meningkatkan taraf kesejahteraan sosialnya (Sumodiningrat, 2009; Aditya et al., 2018; Rizka et al., 2016). Salah satu KUBE di Dusun Mavilla Rengganis adalah Kelompok Usaha Bersama (KUBE) Jupiter Jaya. Kelompok Usaha ini beranggotakan 10 orang yang terdiri dari ibu-ibu rumah tangga dan remaja putri yang tinggal di sekitar Dusun Mavilla Rengganis. Kelompok ini terbentuk dari tahun 2018. Aktifitas KUBE selama ini bergerak dibidang usaha kuliner yaitu pembuatan peyek ikan.

Permasalahan utama Kelompok Usaha ini adalah motivasi yang rendah dari anggota kelompok dan kurangnya keahlian yang dimiliki. Kurangnya keahlian ini terkait dengan manajemen usaha yang belum dikelola dengan baik. Hal ini terjadi karena selama ini kelompok tersebut kurang memperoleh pengetahuan tentang manajemen usaha terutama terkait dengan pengemasan, labeling, dan pembukuan usaha.

Aspek kemasan yang digunakan masih sederhana yaitu menggunakan bahan plastik biasa dan belum ada merek. Dilihat dari fungsi untuk melindungi produk kemasan yang digunakan sudah cukup baik, namun dari aspek estetika dan daya tarik produk masih sangat kurang. Usaha peyek ikan tersebut juga belum mempunyai merek. Aspek pengelolaan keuangan selama ini tidak baik. Tidak ada pembukuan yang jelas tentang penjualan yang sudah dilakukan. Selama ini pencatatan hanya dilakukan sembarangan dan tidak dikelola dengan baik sehingga secara financial tidak bisa melihat perkembangan usaha.

Prospek usaha peyek ikan yang dimiliki oleh kelompok ini kedepan sangat menjanjikan, Untuk itu perlu diberikan motivasi melalui pelatihan manajemen usaha. Ada beberapa permasalahan manajemen usaha yang dihadapi oleh mitra, yaitu : (1) Kemasan yang digunakan masih sederhana, hanya menggunakan plastik biasa, (2) labeling masih sederhana dan belum ada merek, dan (3) Tidak ada pembukuan keuangan yang jelas.

Berdasarkan permasalahan mitra maka solusi yang diberikan adalah sebagai berikut : (1) Memberikan pengetahuan mengenai manajemen kemasan dan manajemen labeling, (2) Mengadakan pelatihan pembukuan sederhana untuk usaha, dan (3) Memberikan pendampingan dalam membuat pembukuan usaha. Adapun tujuan dari kegiatan ini adalah untuk meningkatkan motivasi kelompok masyarakat dan daya saing produk dengan memberikan pelatihan manajemen usaha bagi KUBE Jupiter Jaya. Kelompok Usaha ini bergerak di bidang kuliner yaitu dengan produksi peyek ikan. Peyek ikan berbahan dasar ikan teri kaca. Peyek ikan ini potensial untuk dikembangkan menjadi usaha oleh-oleh khas Lombok. 


\section{Metode Pengabdian}

Dalam kegiatan ini akan diterapkan pelatihan dengan metode pembelajaran yaitu pendekatan ceramah, diskusi dan praktek.

a) Pendekatan ceramah dilakukan untuk memberikan pemahaman kepada mitra tentang pentingnya manajemen usaha. Mitra akan diberikan pengetahuan tentang bagaimana manajemen kemasan, manajemen labeling dan manajemen keuangan usaha.

b) Pendekatan diskusi dilakukan untuk mendapatkan umpan balik tentang pengetahuan yang sudah diterima mitra. Dari diskusi akan diperoleh informasi tentang sejauhmana pemahaman mitra terhadap pengetahuan yang sudah diberikan.

c) Praktek dan pendampingan pembuatan pembukuan sederhana. Peserta dilatih dan didampingi untuk membuat pembukuan usaha secara manual.

Langkah-langkah kegiatan ini dilakukan dengan melalui beberapa tahap yaitu meliputi:

a) Persiapan

Bertujuan untuk menyiapkan segala kebutuhan dalam pelaksanaan kegiatan yang meliputi :

* koordinasi dengan mitra.

* penentuan waktu pelaksanaan.

* menjalin kerjasama dengan mitra

* dan persiapan alat dan bahan yang dibutuhkan untuk pelatihan.

b) Pelaksanaan

Pelaksanaan kegiatan pengabdian dilakukan dengan melibatkan mitra. Adapun pelatihan yang diberikan kepada mitra adalah tentang manajemen usaha. Selanjutnya mitra diberikan pula pelatihan dan pendampingan dalam membuat pembukuan usaha.

c) Evaluasi dan tindak lanjut

Evaluasi terhadap peningkatan kemampuan mitra sebelum dan sesudah pelatihan. Evaluasi dilakukan dengan menggunakan angket, obervasi dan wawancara. Adapun indikator keberhasilan pelatihan ini adalah :

1) Semua peserta $(100 \%)$ hadir dalam pelatihan

2) Lebih dari $90 \%$ peserta yang hadir memahami materi yang diberikan

3) Lebih dari $80 \%$ peserta menyatakan materi yang diberikan sangat bermanfaat

4) Lebih dari $90 \%$ peserta memiliki motivasi untuk menerapkan manajemen usaha

5) Lebih dari $90 \%$ peserta mampu membuat pembukuan usaha.

\section{Hasil Pengabdian dan Pembahasan}

Pada tahap persiapan Tim Pengabdian Kepada Masyarakat Universitas Pendidikan Mandalika mengunjungi mitra untuk berdiskusi tentang beberapa hal terkait dengan kesiapan mitra dalam menerima kunjungan tim. Selain itu tim dan mitra menentukan waktu yang tepat untuk pelaksanaan kegiatan dan administrasi lainnya. Kegiatan ini akan dilaksanakan selama 2 bulan. Waktu pelaksanaan kegiatan dimulai pada tanggal 3 Januari 2021 bertempat dirumah ibu ketua KUBE Jupiter Jaya. Kegiatan tersebut berlangsung dari tanggal 3 Januari 2021 sampai dengan 28 Februari 2021. Pelaksanaan kegiatan dimulai dari pukul 08.00 wita dan berakhir pukul 14.00 wita.

Terdapat dua pendekatan yang digunakan dalam pelaksanaan kegiatan ini, yaitu pendekatan pelatihan dan pendampingan. Kegiatan pertama berlangsung selama 4 minggu yaitu pelatihan dan pendampingan manajemen kemasan dan labeling produk. Mitra 
mendapatkan pengetahuan bagaimana harus mengemas dan labeling produk sehingga produk tersebut mempunyai daya tarik bagi konsumen. Untuk kegiatan kedua terlaksana selama 4 minggu yaitu pelatihan dan pendampingan pembukuan usaha. Mitra memperoleh pengetahuan bagaimana membuat pembukuan usaha yang benar dan sesuai dengan standar yang berlaku.
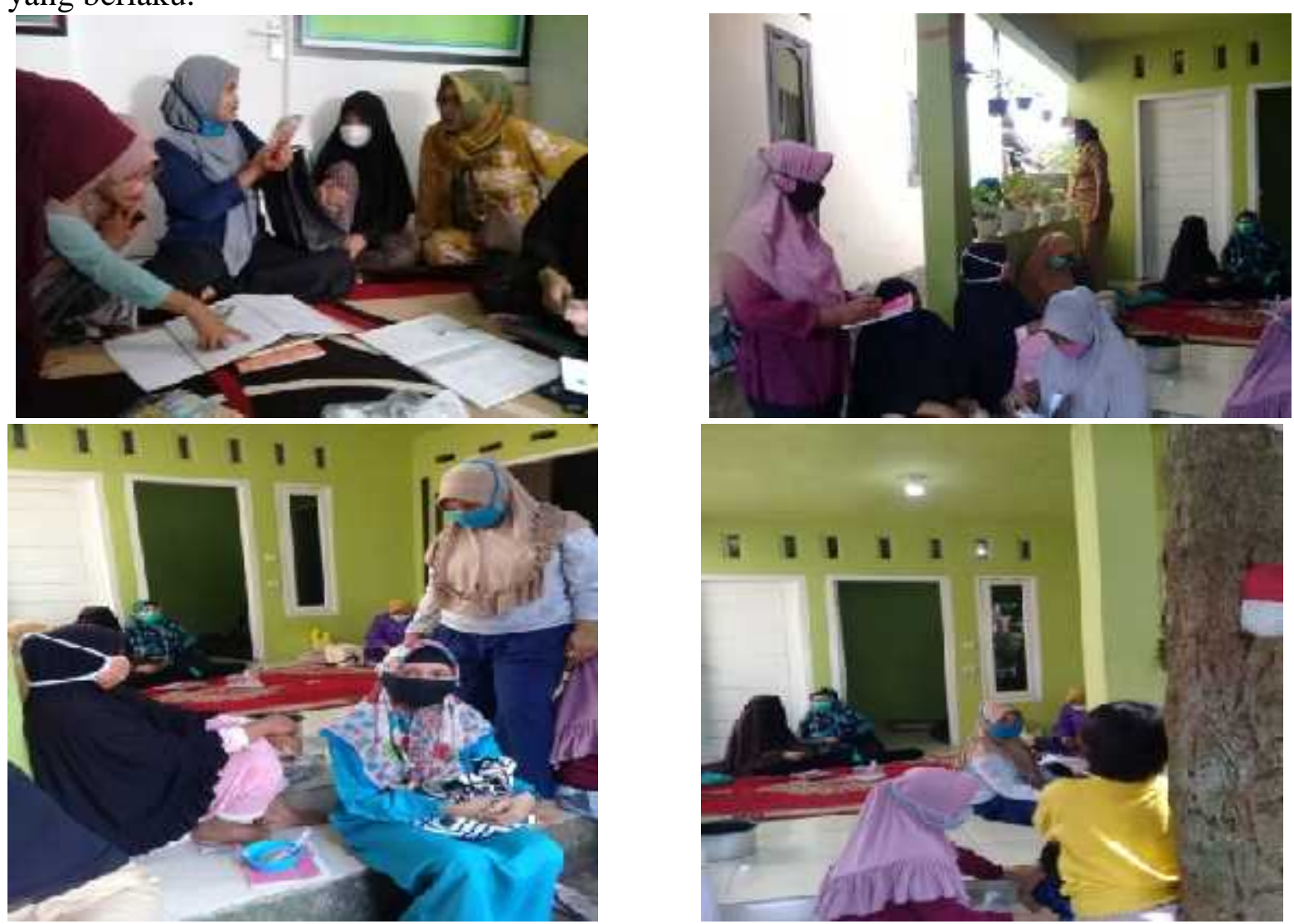

\section{Gambar 1. Dokumentasi Kegiatan Pengabdian Kepada Masyarakat Di Lapangan}

Berikut ini hasil pelaksanaan kegiatan pengabdian kepada masayarakat meliputi:

\section{1) Aspek Keuangan}

Sebelum kegiatan dilakukan dan berdasarkan diskusi dengan Mitra diperoleh informasi bahwa mitra belum memahami manajemen keuangan dalam hal ini membuat pembukuan sederhana untuk usaha. Indikator belum memahami adalah belum adanya pembukuan usaha yang jelas sehingga mitra tidak mengetahui sejauhmana perkembangan usaha selama ini dilihat dari aspek finansial.

Setelah pelatihan pembukuan sederhana dilakukan lebih dari $90 \%$ peserta pelatihan memahami dan dapat membuat pembukuan usaha. Hal ini bermanfaat ke depannya jika mitra ingin mengembangkan usahanya melalui perbankan. Mitra cukup antusias dan berminat melakukan akses perbankan, untuk mendapatkan tambahan modal. Awalnya mitra belum membuat pembukuan usaha, dengan alasan belum sempat dan perputaran keuangan relatif kecil. Dengan pembinaan dan pendampingan secara kontinu, mitra mau dan dapat membuat pembukuan usaha.

\section{2) Aspek Kemasan Produk}

Sebelum kegiatan pelatihan dilakukan kemasan produk mitra hanya menggunakan plastik biasa sekedar hanya untuk melindungi produk. Selama pelatihan dilakukan tim 
pengabdian kepada masyarakat memberikan penjelasan kepada mitra tentang pentingnya tampilan luar (kemasan) untuk menarik konsumen. Kemasan selain berfungsi untuk melindungi produk, kemasan harus juga mempertimbangkan aspek estetika sehingga menjadi daya tarik bagi konsumen. Kemasan yang digunakan adalah kemasan stand pouch. Alasan penggunaan stand pouch adalah kemasan stand pouch lebih praktis, tampilan desain pada stand pouch terlihat kuat, bentuknya sangat fleksibel, kemasan stand pouch terdiri dari berbagai ukuran, tersedia dalam berbagai warna, harga ekonomis,tampilan lebih modern dan menarik.

\section{3) Labeling}

Untuk labeling selama ini hanya menggunakan labeling sederhana dengan menggunakan labeling yang di print hitam putih saja. Setelah mendapatkan pelatihan manajemen labeling, mitra sepakat untuk menganti label yang berwarna sehingga terlihat lebih menarik. Untuk merek produk, mitra juga sepakat memberikan merek Peyek Ikan Dua Sekawan.

Tindak lanjut jangka pendek dari kegiatan ini direncanakan akan dilakukan pengawasan kepada mitra. Tim akan memonitor kegiatan mitra, pendampingan, memberikan arahan serta solusi bagi segala permasalahan yang terjadi terkait dengan manajemen usaha. Kegiatan pengawasan akan diorganisir sepenuhnya oleh tim pengabdian kepada masyarakat. Kegiatan ini akan dilakukan secara berkelanjutan. Rencana jangka panjang target berikutnya adalah KUBE akan dikembangkan menjadi sebuah lembaga koperasi.

\section{Kesimpulan}

Kesimpulan yang diperolah dari hasil kegiatan pengabdian ini adalah pelatihan manajemen usaha sangat bermanfaat bagi mitra yaitu adanya peningkatan pengetahuan dan keterampilan dalam manajemen usaha meliputi kemampuan mitra membuat pembukuan sederhana, mitra memahami pentingnya menggemas produk agar lebih menarik dan mitra juga memahami pentingnya memberikan label pada suatu produk.

\section{Saran}

Perlu pembinaan dan pendampingan dalam usaha pemasaran produk sehingga UMKM bisa survive dan berkembang. Selain itu sebaiknya dilakukan juga pengurusan ijin PIRT agar konsumen yakin akan keamanan produk makanan yang dihasilkan oleh mitra.

\section{Daftar Pustaka}

Aditya, R., Tamba, W., \& Arief Rizka, M. (2018). Evaluasi Implementasi Program Kelompok Usaha Bersama (KUBE) dalam Mengatasi Kemiskinan di Kota Mataram. Jurnal Kependidikan: Jurnal Hasil Penelitian dan Kajian Kepustakaan di Bidang Pendidikan, Pengajaran dan Pembelajaran, 4(2), 192-197. doi:https://doi.org/10.33394/jk.v4i2.1129

Departemen Koperasi. (2008). PDB, Investasi, Tenaga Kerja, Nilai Ekspor UKM di Indonesia. Depkop. Jakarta.

Gaol, CHR., Jimmy L. (2014). A to Z Human Capital (Manajemen Sumber Daya Manusia) Konsep, Teori, dan Pengembangan dalam Konteks Organisasi Publik dan Bisnis, PT. Gramedia Widiasarana, Jakarta. 
Hasyim, Diana. (2013). Kualitas Manajemen Keuangan Usaha Mikro Kecil Menengah (Umkm) (Studi Kasus Pada Distribution Store (Distro) Di Kota Medan). Jurnal Jupiis Vol 5 No 2.

Kotler, Philip. (2005). Marketing Management, Milenium Edition,Prentice Hall.

Sulaeman, dan Suhendar. (2004). Pengembangan Usaha Kecil dan Menengah Dalam Menghadapi Pasar Regional dan Global. Infokop nomor 25 tahun XX.

Miswaty, T., Syamsurrijal. S., Hadi, M., Ulfa, B. (2020). Pelatihan Bahasa Inggris Dan Pembukuan Keuangan Bagi Masyarakat Desa Langko. Jurnal Pengabdian Undikma., 1(2), 166-171. doi:https://doi.org/10.33394/jpu.v1i2.3082.

Rizka, M., Primawati, S., \& Mursali, S. (2016). IbM Pelatihan Pembuatan "Kerja Mas" (Keripik Jagung Manis) Berbasis Agropreneur. Jurnal Kependidikan: Jurnal Hasil Penelitian dan Kajian Kepustakaan di Bidang Pendidikan, Pengajaran dan Pembelajaran, 2(2). doi:https://doi.org/10.33394/jk.v2i2.456

Sumodiningrat, Gunawan. (2009). Pemberdayaan Masyarakat. Jakarta. PT Gramedia Pustaka Utama 